\title{
NUMERICAL STUDY ON RANDOM WAVES AND WAVE-INDUCED LONG- SHORE CURRENTS AT LEADBETTER BEACH
}

Lei Cui

State Key Laboratory of Coastal and Offshore Engineering, Dalian University of Technology, Dalian 116023, P. R. China., trulysignory@163.com

Jun Tang

State Key Laboratory of Coastal and Offshore Engineering, Dalian University of Technology, Dalian 116023, P. R. China.

Follow this and additional works at: https://jmstt.ntou.edu.tw/journal

Part of the Civil and Environmental Engineering Commons

\section{Recommended Citation}

Cui, Lei and Tang, Jun (2011) "NUMERICAL STUDY ON RANDOM WAVES AND WAVE-INDUCED LONG-SHORE CURRENTS AT LEADBETTER BEACH," Journal of Marine Science and Technology. Vol. 19: Iss. 2, Article 14. DOI: $10.51400 / 2709-6998.2157$

Available at: https://jmstt.ntou.edu.tw/journal/vol19/iss2/14

This Research Article is brought to you for free and open access by Journal of Marine Science and Technology. It has been accepted for inclusion in Journal of Marine Science and Technology by an authorized editor of Journal of Marine Science and Technology. 


\section{NUMERICAL STUDY ON RANDOM WAVES AND WAVE-INDUCED LONG-SHORE CURRENTS AT LEADBETTER BEACH}

\section{Acknowledgements}

This research was financially supported by the Scientific Research Foundation of the Higher Education Institutions of Liaoning Province under Grant No. 2006T018, and by the National Natural Science Foundation of P. R. China under Grant No. 50839001. 


\title{
NUMERICAL STUDY ON RANDOM WAVES AND WAVE-INDUCED LONG-SHORE CURRENTS AT LEADBETTER BEACH
}

\author{
Lei Cui* and Jun Tang*
}

Key words: water waves, parabolic mild slope equation, radiation stresses, wave-induced long-shore currents, numerical modeling.

\begin{abstract}
Shallow coastal zone is extremely dynamic region, where the hydrodynamics are complicated as evident in the refraction, diffraction, shoaling and breaking of water waves, as well as the presence of wave-induced near-shore currents. In this paper, the distribution of waves and wave-induced long-shore currents formed by the breaking of obliquely incident random waves at Leadbetter Beach, Santa Barbara, USA are numerically studied. In the present numerical models, the random water waves are simulated based on the parabolic mild slope equation, and so the wave radiation stresses exerted on waveinduced currents are calculated based on variables in the parabolic mild slope equation, and the wave-induced longshore currents are simulated based on these. The numerical results have also been validated by field data and show good agreement with field data. In the process of numerical modeling, it is found that the bathymetry gradient is determinant to the distribution of wave transformation and wave-induced long-shore current in this coastal zone. In the areas where the bathymetry gradients are greater, the break line is closer from the shoreline, and the radiation stresses and radiation stress gradients are both greater than else areas associating with the presence of the relatively greater maximum wave heights, which result in slightly greater wave-induced long-shore currents, whereas, in the areas where the bathymetry gradients are smaller, the distribution of the break line, wave heights and wave-induced long-shore currents are just opposite. On the side, the wave-induced long-shore current deflects with the variation of bathymetry gradients.
\end{abstract}

Paper submitted 02/04/10; revised 04/09/10; accepted 05/05/10. Author for correspondence: Lei Cui (e-mail: trulysignory@163.com).

*State Key Laboratory of Coastal and Offshore Engineering, Dalian University of Technology, Dalian 116023, P. R. China.

\section{INTRODUCTION}

As waves travel from deep to shallow water, the combination effect of refraction, diffraction, shoaling and breaking will take place, and the wave-induced near-shore currents will be formed and developed when waves break strongly in surf zones accordingly [20]. The coastal waves and wave-induced nearshore currents are generally regarded as the most important hydrodynamics for coastal water exchanging, sediment transport and pollutant diffusion. It is very crucial to understand the distribution of them for coastal engineering and environment protecting.

Many authors have studied and developed theories for the wave-induced near-shore currents. Longuet-Higgins and Stewart [19] proposed the theory of wave radiation stresses firstly and expatiated the generation mechanism for the waveinduced near-shore currents in terms of wave radiation stresses. Subsequently, some authors [2, 4, 6, 7, 16-18, 21, 27, 32, 33] studied various aspects of the radiation stresses for linear water waves and proposed formulas. Much progress on other influential factors of the wave-induced near-shore currents like bottom frictional stress, lateral mixing stress, the varying of mean water level and so on has also been made [11, 12, 22, 23, 29, 31, 34-36]. Based on the foundational research mentioned above, many authors [1, 10, 15, 24, 26, 30, 37] have made both numerical modeling and experiment research on the coastal water waves and wave-induced near-shore currents. Due to the complexity of hydrodynamics in shallow coastal zones, the farther study is still needed, especially in the representative coastal zones.

The numerical modeling is an effective way to describe the coastal hydrodynamics and can provide available information for engineering problems. The distribution of coastal waves and wave-induced near-shore currents can be numerically simulated by the parabolic mild slope equation based on the linear wave theory and near-shore currents mathematical model, where the radiation stresses exerted on wave-induced near-shore currents are calculated by the wave amplitude complex in the parabolic mild slope equation. In this paper, the random water waves and wave-induced long-shore currents formed by the breaking of obliquely incident random waves at Leadbetter Beach, Santa Barbara, USA are numeri- 
cally studied based on the mathematical models mentioned above. The mathematical models are numerically simulated based on the finite difference method. The numerical results have also been validated by field data, and the comparisons between the simulated results and field data show good agreement. The behaviors of random waves transformation and distribution of wave-induced long-shore currents at this coastal zone are also described based on the present numerical models.

\section{MATHEMATICAL MODELS}

The present models consist of two computationally distinct numerical models: wave height transformation model and nearshore current model.

\section{Wave Height Transformation Model}

As the obliquely incident random waves propagate in coastal zone, the wave-induced long-shore currents will be formed by the distortion and breaking of waves. The foundation to simulate the long-shore current is to calculate the wave transformation firstly. If the reflection and diffraction effects are ignored when waves propagate forward in the main direction, the parabolic mild slope equation can be effectively applied to simulate coastal water wave transformation. The present model for random wave height transformation is established based on the parabolic mild slope equation given by Kirby [14]:

$$
\begin{aligned}
& \sum_{n=1}^{n} C_{g n} \frac{\partial A_{n}}{\partial x}+\sum_{n=1}^{N}\left(\mathrm{i}\left(\bar{k}_{n}-a_{0} k_{n}\right) C_{g n}+\frac{\mathrm{i} C_{g n}}{2} D\left|A_{n}\right|^{2}+\frac{1}{2} \frac{D_{b}}{E}+\frac{1}{2} \frac{\partial C_{g n}}{\partial x}\right) A_{n} \\
& -\sum_{n=1}^{N} \frac{b_{1}}{\omega_{n} k_{n}} \frac{\partial^{2}}{\partial x \partial y}\left(C_{n} C_{g n} \frac{\partial A_{n}}{\partial y}\right) \\
& +\sum_{n=1}^{N}\left(\frac{\mathrm{i}}{\omega_{n}}\left(a_{1}-b_{1} \frac{\bar{k}_{n}}{k_{n}}\right)+\frac{b_{1}}{\omega_{n}}\left(\frac{\left(k_{n}\right)_{x}}{k_{n}^{2}}+\frac{\left(C_{g n}\right)_{x}}{2 k_{n} C_{g n}}\right)\right) \frac{\partial}{\partial y}\left(C_{n} C_{g n} \frac{\partial A_{n}}{\partial y}\right)=0
\end{aligned}
$$

in which

$$
\begin{gathered}
D=k_{n}^{3} \frac{C_{n}}{C_{g n}} \frac{\left(\cosh \left(4 k_{n} h\right)+8-2 \tanh ^{2}\left(k_{n} h\right)\right)}{8 \sinh ^{4}\left(k_{n} h\right)} \\
D_{b}=\frac{K C_{g n}}{h}\left(E_{n}-E_{s n}\right) \\
\bar{k}_{n}=\frac{1}{B} \int_{0}^{B} k_{n}(x, y) d y
\end{gathered}
$$

where $x$ and $y$ are the coordinates describing the horizontal plane, and the positive direction of $x$-axis is seaward; $\mathbf{i}$ is the imaginary unit; $h$ is the local water depth; $N$ is the number of discretizations in frequency; index $n$ is used to represent the $n$-th regular wave component; $A_{n}(x, y)$ is the slowly varying wave amplitude complex; $\omega_{n}$ is the wave angular frequency; $k_{n}$ is the local wave number; $\bar{k}_{n}$ is the representative value of wave number, where $B$ is the width of the domain; $C_{n}=\omega_{n} / k_{n}$ is the phase velocity; $C_{g n}=\partial \omega_{n} / \partial k_{n}$ is the group velocity; $E_{n}=\rho g A_{n}{ }^{2} / 2$ is the wave energy, where $\rho$ is the water density and $g$ is the gravity acceleration; $E_{s n}$ is the wave energy where the wave height is stable after wave breaking and have the value of $E_{n}$ under $0.4 h$ in this paper [5]; the coefficients $a_{0}, a_{1}$ and $b_{1}[14]$ depend on the aperture width chosen to specify the minimax approximation; $D$ is the non-linear dispersion term according to the Stokes wave; $D_{b}$ is the energy dissipation term; $K \approx 0.15$ is an experiential coefficient.

The incident random water waves can be discretized as a series regular wave components by the offshore wave spectrum $S(\omega)$, which indicates the distribution of wave energy over wave frequencies. Based on the offshore wave spectrum, the incident wave amplitudes are discretized in frequency as:

$$
a_{n}=\sqrt{2 S(\omega) \Delta \omega}
$$

The water surface elevation is represented by

$$
\eta=\sum_{n} \eta_{n}=\operatorname{Re}\left\{\sum_{n=1}^{N} A_{n}(x, y) e^{i\left(\bar{k}_{n} x-\omega_{n} t\right)}\right\}
$$

$A_{n}(x, y)$ can be expressed as:

$$
A_{n}(x, y)=a_{n} e^{\mathrm{i}\left(\left(k_{n} \cos \theta-\bar{k}_{n}\right) x+k_{n} \sin \theta y\right)}
$$

where $\theta$ is the angle from the principal direction of wave propagation.

The transformation of each wave height component is determined with the monochromatic mild slope parabolic model. The statistical characteristics at the grid point are obtained by assembling the wave components by linear superposition. The root mean square wave height $H_{\mathrm{rms}}$ is calculated as:

$$
H_{\mathrm{rms}}(x, y)=2 \sqrt{\sum_{n=1}^{N}\left|A_{n}(x, y)\right|^{2}}
$$

As waves propagate in coastal zone, the wave breaking will occur and the wave energy will be dissipated. In the wave height transformation model, it is assumed that waves begin to break when the simulated wave height $H(x, y)$ is greater than the wave height $H_{b}$ at the breaking point. In shallow water, the breaking wave height $H_{b}$ can be usually defined as follows [9]:

$$
H_{b}=\min (\gamma h, 0.14 L \tanh k h)
$$


where $Y$ is the wave breaker index; $L$ is wave length.

The incident and lateral boundary conditions would be specified in the present wave height transformation model. The incident wave amplitude complex for each offshore wave component is specified as:

$$
A_{n}\left(x_{0}, y\right)=A_{0 n} e^{\mathrm{i}\left(\left(k_{0 n} \cos \theta_{0}-\bar{k}_{n}\right) x_{0}+k_{0 n} \sin \theta_{0} y\right)}
$$

where $\left(x_{0}, y\right)$ is the coordinate of incident boundary; $A_{0 n}$ is the $n$-th incident wave amplitude; $\theta_{0}$ is the incident angle from the principal direction of wave propagation; $k_{0 n}$ is the $n$-th wave number at the incident boundary.

For each wave component, the lateral boundary condition can be specified as [13]:

$$
\frac{\partial A_{n}}{\partial y}=\mathrm{i} c_{r} A_{n} k_{n} \sin \theta
$$

where $c_{r}$ is the boundary reflection parameter. Since the angle $\theta$ at the lateral boundary is hard to calculate and the calculation of wave amplitude by the parabolic mild slope equation is carried out along the dominant direction step by step generally, $k_{n} \sin \theta$ can be estimated by the correlative variables at the previous step as:

$$
c_{r}\left(k_{n} \sin \theta\right)_{i+1, j-1 / 2} \approx-\frac{2 \mathrm{i}}{\Delta y} \frac{A_{n i, j}-A_{n i, j-1}}{A_{n i, j}+A_{n i, j-1}}
$$

where $\Delta y$ is the spatial space along the $y$-axis. Based on Eq. (9), Eq. (8) can be discretized by the finite difference method as:

$$
\frac{A_{n i+1, j}-A_{n i+1, j-1}}{\Delta y}=\mathrm{i} c_{r}\left(k_{n} \sin \theta\right)_{i+1, j-1 / 2} \frac{A_{n i+1, j}+A_{n i+1, j-1}}{2}
$$

Eq. (1) is solved by using an algorithm for solving tridiagonal systems, combining with the Crank-Nicolson finite difference scheme.

\section{Near-Shore Current Model}

The near-shore current model is based on the concept of radiation stress, which indicates the excess of momentum flux due to wave propagation. The depth-integrated equations of motion and water conservation can be described as:

$$
\begin{gathered}
\frac{\partial \eta}{\partial t}+\frac{\partial}{\partial x}(U(h+\eta))+\frac{\partial}{\partial y}(V(h+\eta))=0 \\
\frac{\partial U}{\partial t}+U \frac{\partial U}{\partial x}+V \frac{\partial U}{\partial y}+g \frac{\partial \eta}{\partial x}+\frac{1}{\rho(h+\eta)}\left(\frac{\partial S_{x x}}{\partial x}+\frac{\partial S_{x y}}{\partial y}\right) \\
-\frac{1}{\rho(h+\eta)}\left(\tau_{\eta x}-\tau_{b x}\right)-A_{m x}=0
\end{gathered}
$$

$$
\begin{gathered}
\frac{\partial V}{\partial t}+U \frac{\partial V}{\partial x}+V \frac{\partial V}{\partial y}+g \frac{\partial \eta}{\partial y}+\frac{1}{\rho(h+\eta)}\left(\frac{\partial S_{y x}}{\partial x}+\frac{\partial S_{y y}}{\partial y}\right) \\
-\frac{1}{\rho(h+\eta)}\left(\tau_{\eta y}-\tau_{b y}\right)-A_{m y}=0
\end{gathered}
$$

where $t$ is the time; $U$ and $V$ are the depth-integral current velocity components in $x$ and $y$ directions respectively; $\eta$ is the mean elevation of free water surface; $S_{x x}, S_{x y}, S_{y x}$ and $S_{y y}$ are the radiation stress components; $\tau_{\eta x}$ and $\tau_{\eta y}$ are the shear stress components of wind to water surface, and both of them are ignored in the paper; $\tau_{b x}$ and $\tau_{b y}$ are the bottom shear stress components; $A_{m x}$ and $A_{m y}$ are the lateral mixing terms in $x$ and $y$ directions respectively.

The concept of radiation stress was proposed by Longuethiggins and Stewart [19] firstly. The expression deduced from the parabolic mild slope equation for the radiation stresses may be written as [33]:

$$
\begin{aligned}
S_{x x}= & \frac{\rho g}{4}\left(\left|\frac{\partial A}{\partial x}+\mathrm{i} \bar{k} A\right|^{2} \frac{1}{k^{2}}\left(1+\frac{2 k h}{\sinh 2 k h}\right)+|A|^{2} \frac{2 k h}{\sinh 2 k h}\right. \\
& \left.+\frac{2 k h / \tanh 2 k h-1}{2 k^{2}}\left(\left|\frac{\partial A}{\partial x}+\mathrm{i} \bar{k} A\right|^{2}+\left|\frac{\partial A}{\partial y}\right|^{2}-k^{2}|A|^{2}\right)\right)
\end{aligned}
$$

$$
\begin{aligned}
S_{y y}= & \frac{\rho g}{4}\left(\left|\frac{\partial A}{\partial y}\right|^{2} \frac{1}{k^{2}}\left(1+\frac{2 k h}{\sinh 2 k h}\right)+|A|^{2} \frac{2 k h}{\sinh 2 k h}\right. \\
& \left.+\frac{2 k h / \tanh 2 k h-1}{2 k^{2}}\left(\left|\frac{\partial A}{\partial x}+\mathrm{i} \bar{k} A\right|^{2}+\left|\frac{\partial A}{\partial y}\right|^{2}-k^{2}|A|^{2}\right)\right)
\end{aligned}
$$

$S_{x y}=S_{y x}=\frac{\rho g}{4}\left(\operatorname{Re}\left(\left(\frac{\partial A}{\partial x}+\mathrm{i} \bar{k} A\right) \frac{\partial A^{*}}{\partial y}\right) \frac{1}{k^{2}}\left(1+\frac{2 k h}{\sinh 2 k h}\right)\right)$

where $A^{*}$ is the conjugate complex of $A$. The statistical characteristics of radiation stresses in the near-shore current model are obtained by assembling the radiation stress components corresponding to each wave component by linear superposition as:

$$
\begin{gathered}
S_{x x}=\sum_{n=1}^{N} S_{x x, n} \\
S_{y y}=\sum_{n=1}^{N} S_{y y, n} \\
S_{x y}=\sum_{n=1}^{N} S_{x y, n}
\end{gathered}
$$




$$
S_{y x}=\sum_{n=1}^{N} S_{y x, n}
$$

The principle of water bottom shear stress influenced by the waves and currents is complex. In the present model, a linearized bottom friction model $[3,17]$ is adopted:

$$
\begin{aligned}
& \tau_{b x}=\frac{4}{\pi} \rho c_{f} u_{0} U \\
& \tau_{b y}=\frac{2}{\pi} \rho c_{f} u_{0} V
\end{aligned}
$$

where $u_{0}$ is the amplitude of wave orbital velocity and calculated as $u_{0}=2 \pi a_{0} / T$, in which $T$ is the wave period; $a_{0}=$ $H /(2 \sinh k h) ; c_{f}$ is the bed shear stress coefficient.

The lateral mixing terms $A_{m x}$ and $A_{m y}$ influence the distribution of near-shore current velocity in surf zone and can be expressed as:

$$
\begin{aligned}
& A_{m x}=\frac{\partial}{\partial x}\left(\mu \frac{\partial U}{\partial x}\right)+\frac{\partial}{\partial y}\left(\mu \frac{\partial U}{\partial y}\right) \\
& A_{m y}=\frac{\partial}{\partial x}\left(\mu \frac{\partial V}{\partial x}\right)+\frac{\partial}{\partial y}\left(\mu \frac{\partial V}{\partial y}\right)
\end{aligned}
$$

where the lateral mixing coefficient $\mu$ is specified as [12]:

$$
\mu=\lambda x_{l} \sqrt{g h}
$$

in which $x_{l}$ is the distance from the wave breaking point $x_{b}$ to the shoreline; $\lambda$ is an adjusted coefficient. It is assumed a constant value of $\mu$ outside the surf zone, which is equal to the value of $\mu$ at the wave breaking point.

The theoretical formulation of near-shore current model constitutes an initial and boundary value problem. It is specified $U=V=\eta=0$ at the far offshore boundary, and $\partial U / \partial \mathbf{n}=$ $V=\partial \eta / \partial \mathbf{n}=0$ along the shoreline boundary, where $\mathbf{n}$ is the direction of outer normal. For the open lateral boundary, we specify $\partial U / \partial \mathbf{n}=\partial V / \partial \mathbf{n}=\partial \eta / \partial \mathbf{n}=0$. At the initial moment, it is specified as $U=V=\eta=0$.

The ADI method is applied for solving the present nearshore current model with the finite difference scheme.

\section{APPLICATION OF THE NUMERICAL MODELS}

Three days field measure data of Near-shore Sediment Transport Study (NSTS) [8, 28] at Leadbetter Beach, Santa Barbara, USA are applied for validating the present wave height transformation model and near-shore current model. The beach profiles for three days are read off on the enlarged
Table 1. Field measured and numerical modeling parameters.

\begin{tabular}{|c|c|c|c|c|c|c|c|c|c|c|}
\hline Case & $\begin{array}{c}\text { Date } \\
(1980)\end{array}$ & $h_{0} / \mathrm{m}$ & $f_{p} / \mathrm{Hz}$ & $H_{\mathrm{rms}} / \mathrm{m}$ & $\theta_{0}$ & $\gamma$ & $c_{f 1}$ & $\lambda_{1}$ & $c_{f 2}$ & $\lambda_{2}$ \\
\hline 1 & Feb. 4 & 9.25 & 0.070 & 0.52 & 19.1 & 0.42 & 0.012 & 0.006 & 0.015 & 0.007 \\
\hline 2 & Feb. 5 & 9.00 & 0.078 & 0.41 & 18.9 & 0.39 & 0.013 & 0.007 & 0.014 & 0.008 \\
\hline 3 & Feb. 6 & 8.80 & 0.090 & 0.26 & 18.7 & 0.30 & 0.020 & 0.007 & 0.022 & 0.007 \\
\hline
\end{tabular}

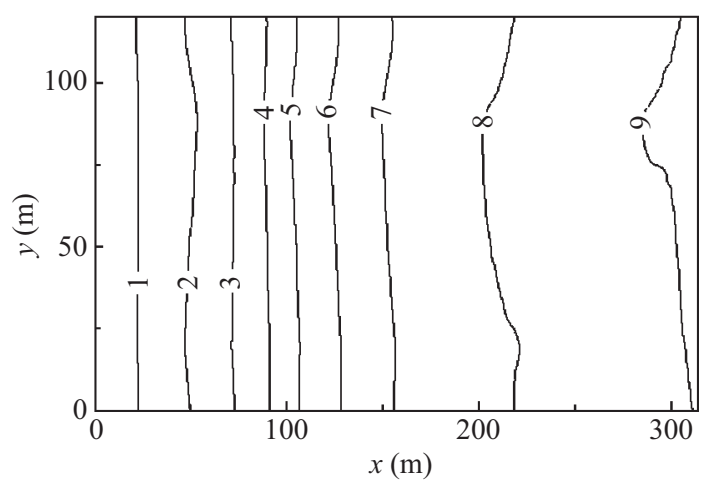

Fig. 1. Near-shore bathymetry at Leadbetter Beach, Santa Barbara, California, USA [28] (unit/m).

copies of respective diagrams in the papers $[8,28]$ on NSTS experiment, and the one on Feb. 4, 1980 is shown in Fig. 1 as representative. The field measured and numerical modeling parameters are shown in Table 1 , where $h_{0}$ is the water depth at the incident boundary; $f_{p}$ is the frequency at the peak of the spectrum. The grid distances in $x$-direction and $y$-direction are $2 \mathrm{~m}$, which are the same values in both the wave height transformation model and the near-shore current model. The time step interval is set $0.1 \mathrm{~s}$ to satisfy the stability requirement. The off-shore direction along $x$ coordinate is set positive. The spectra of wave energy density $S(f)$ for three days are shown in Fig. 2, where $f$ is the frequency. The number of frequency components is 30 . The comparisons of wave heights and longshore currents velocities between the numerically simulated and experiment data along cross-section $y=80 \mathrm{~m}$ for all cases are shown in Fig. 3 and Fig. 5 respectively. The computed wave heights contours based on the random wave transformation model are shown in Fig. 4. The distribution of numerically simulated long-shore currents are shown in Fig. 6. In the progress of numerical modeling, the numerical results of wave heights and near-shore currents based on the regular waves are also accounted for comparing with the present models results. The bed shear stress coefficient $c_{f 1}$ and adjusted parameter $\lambda_{1}$ of the lateral mixing coefficient are used in the present near-shore current model, while $c_{f 2}$ and $\lambda_{2}$ are used in another model based on the regular wave model. The closed circles are the measured data in NSTS experiment. The solid lines are the numerical results based on the present models (named numerical_1 model in the below figures and paragraphs), while the dashed lines are the numerical results based 


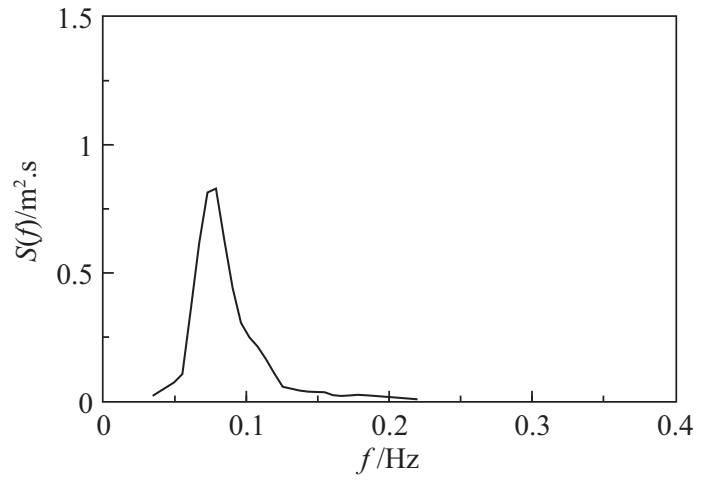

(a) Wave energy density spectra on Feb. 4

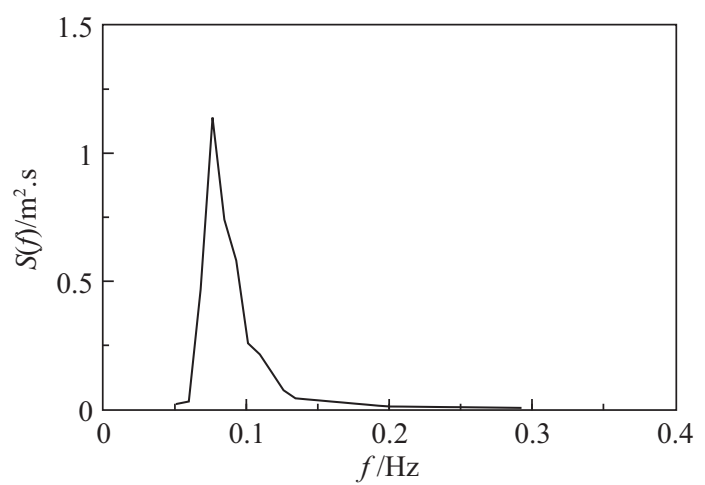

(b) Wave energy density spectra on Feb. 5

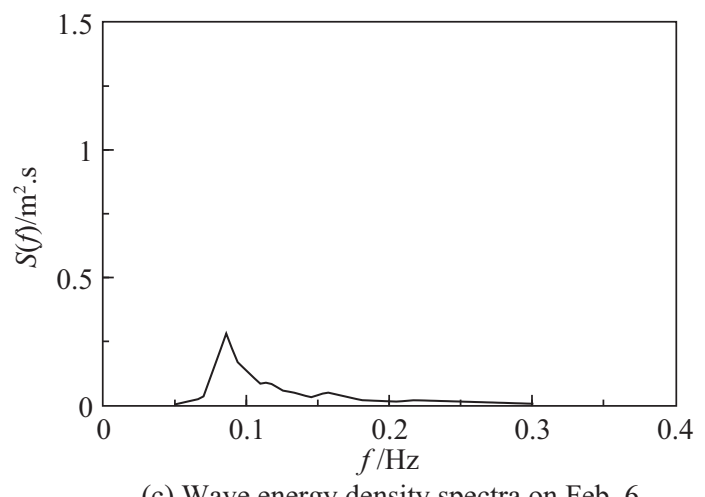

(c) Wave energy density spectra on Feb. 6

Fig. 2. Wave energy density spectra.

on regular wave height transformation model and near-shore current model (named numerical_2 model in the below figures and paragraphs).

After shoaling, the random waves are refracted, diffracted and eventually broken on the beach. The wave breaker index $r$ is determinative to predict the surf zone wave height and ascertain the mean wave break line. In the present random and regular wave height transformation models, the calibrated values of $Y$ are found to get the best fit between the predicted results and measured data. It can be seen in Fig. 3 that the predicted root mean square wave heights $H_{\mathrm{rms}}$ based on both models agree reasonably well with the measured wave heights by using the same value of $r$ for each case, except that the increasing wave height before the maximum $H_{\mathrm{rms}}$ is overpre-

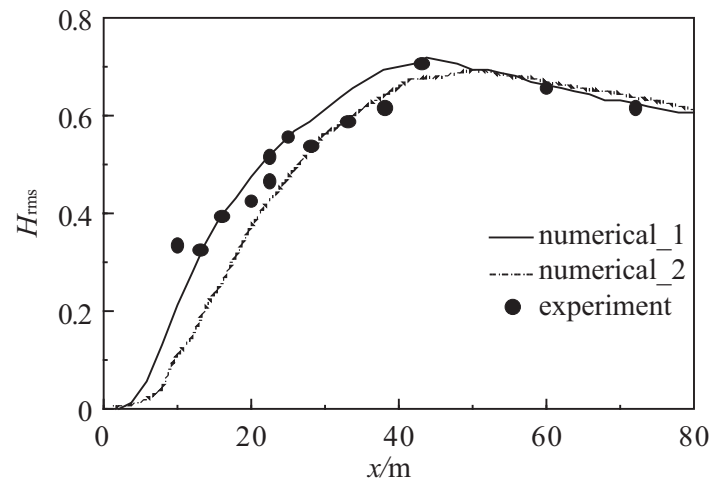

(a) Comparison of observed and computed wave heights on Feb. 4

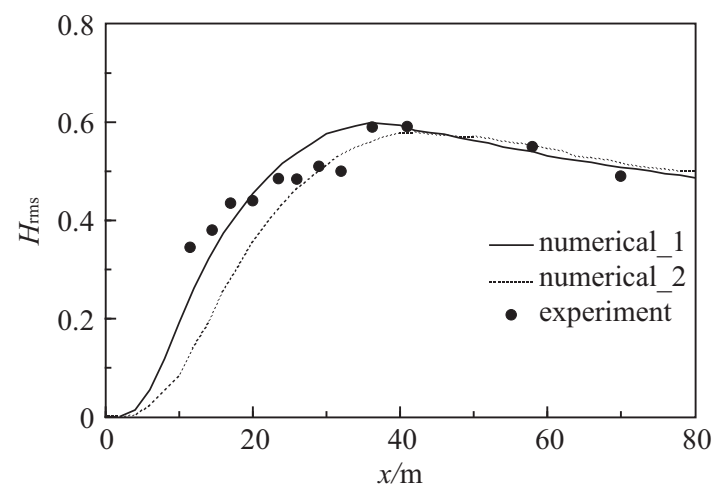

(b) Comparison of observed and computed wave heights on Feb. 5

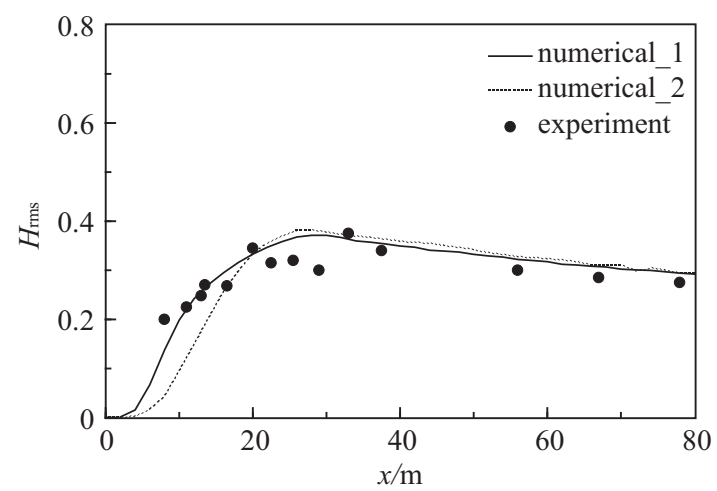

(c) Comparison of observed and computed wave heights on Feb. 6

Fig. 3. Comparison of observed and computed wave heights.

dicted very little on Fig. 3(c). The wave heights increase monotonically before wave breaking and decrease shoreward following a nonlinear relation. It should be pointed out that although the numerical results based on both wave transformation models show good modeling effect, the diminishing wave heights in the surf zone based on the present random wave model are slightly more coincident with the distribution tendency of measured data than those based on the regular wave model.

It can be seen in Fig. 1 that although the water depth gradients in the whole coastal zone are approximately uniform, the values in some areas are still variational, such as the coastal area near $\mathrm{y}=25 \mathrm{~m}$ where the water depth gradients are greater and the area near $\mathrm{y}=90 \mathrm{~m}$ where the water depth 


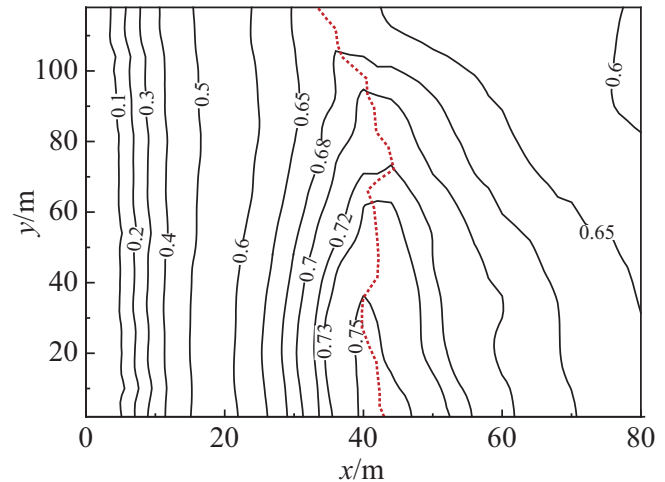

(a) Computed wave heights contours on Feb. 4

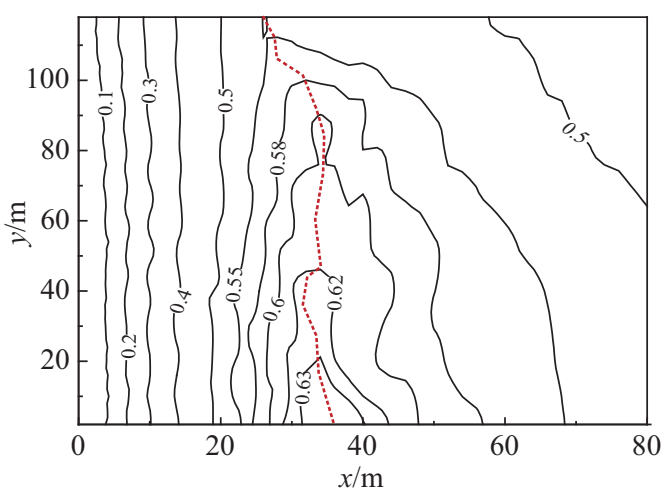

(b) Computed wave heights contours on Feb. 5

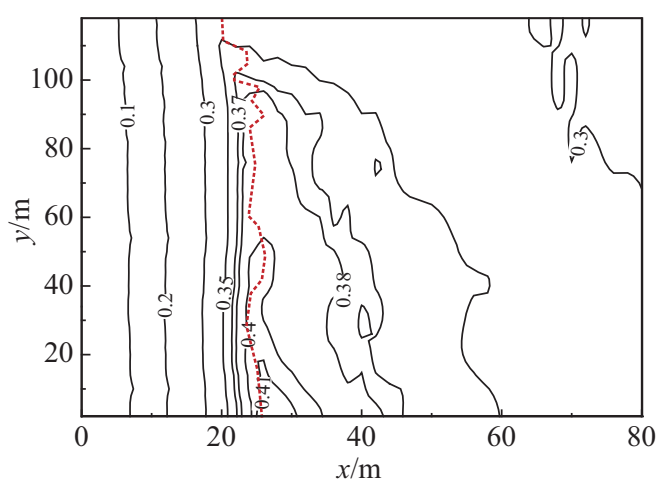

(c) Computed wave heights contours on Feb. 6

Fig. 4. Computed wave heights contours (The wave breaking line is noted by the dashed line).

gradients are less than others area. As is shown in Fig. 4, the waves break at the positions relatively closer from the shore line in the former area, and the maximum wave heights are slightly greater than the values of other area, which is mainly caused by the relatively fast wave energy convergence corresponding to the greater water depth gradients. On the contrary, in the latter area the maximum wave heights are slightly less, and the waves break at the positions relatively far from the shore line.

The wave-induced long-shore currents are generated since the incident waves break on the beach. The convergence and dissipation of wave energy give a gradual change in wave

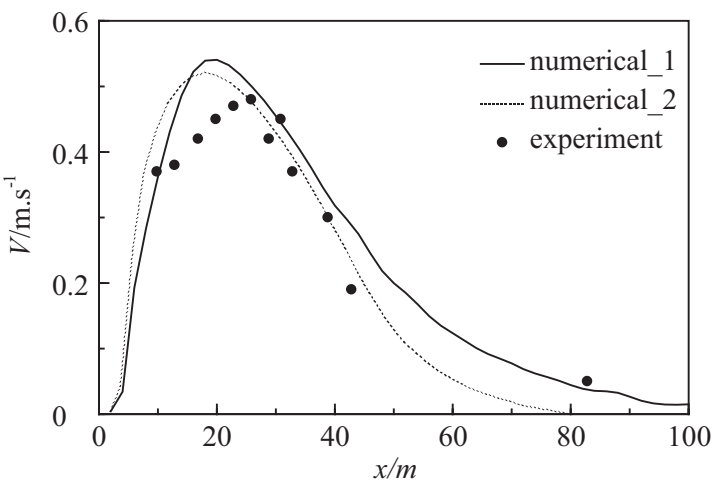

(a) Comparison of observed and computed long-shore current velocity on Feb. 4

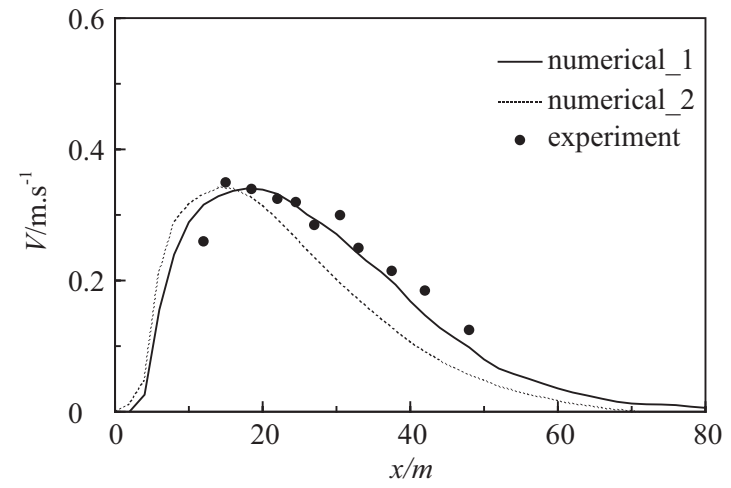

(b) Comparison of observed and computed long-shore current velocity on Feb. 5

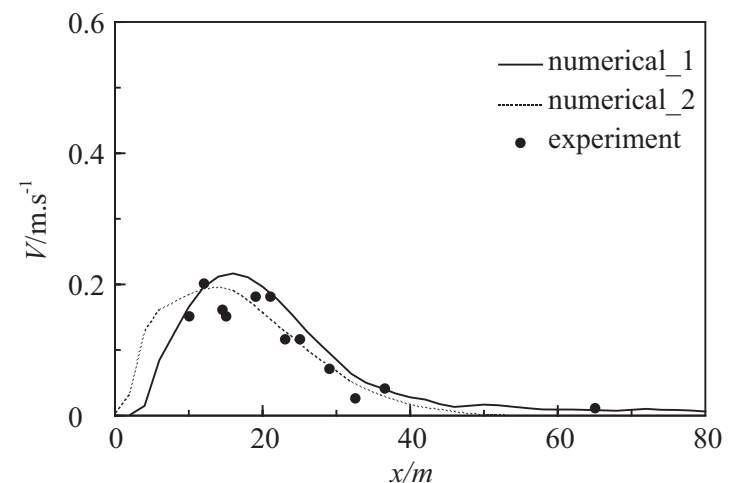

(c) Comparison of observed and computed long-shore current velocity on Feb. 6

Fig. 5. Comparison of observed and computed long-shore current velocity.

radiation stress, which results in a smooth long-shore currents distribution. The comparisons between the numerically simulated and measured data of long-shore currents velocity for three cases are shown in Fig. 5. To simulate the long-shore currents, the near-shore current model parameters $c_{f 1}, \lambda_{1}$ (used in numerical_1 model), $c_{f 2}$ and $\lambda_{2}$ (used in numerical_2 model) are tuned with the experiment data. The bottom friction coefficients $c_{f 1}$ and $c_{f 2}$ mainly affect the magnitude of long-shore currents, while the adjusted parameters $\lambda_{1}$ and $\lambda_{2}$ determine the distribution of long-shore currents. The long-shore cur- 
rents profiles corresponding to the best fit with these calibrated parameters are selected as the solution. Although the values of $c_{f 1}, \lambda_{1}, c_{f 2}$ and $\lambda_{2}$ in each case are different between two models, the discrepancy is very little. It can be seen in Fig. 5 that the maximum mean long-shore currents velocities and the distribution range increase with the increasing of incident wave height accordingly. Compared with Case 3, Case 1 and Case 2 both have the obviously greater mean long-shore currents velocities and distribution range corresponding to the relatively greater incident wave heights. For Case 1, the maximum mean long-shore current velocity is slightly greater than the measured value to obtain the optimal modeling effect. It is also shown in Fig. 5 that the shapes of the measured and numerical computed distribution of the mean long-shore currents velocities differ with the wave breaking location. They are located more shoreward than the wave breaking lines. In the present cases, the maximum mean long-shore currents velocities occur nearly the middle between the shoreline and the location of the maximum $H_{\text {rms. }}$. The main reason is that the maximum value of long-shore current is determined by the wave radiation stress gradient, whereas the maximum value of wave radiation stress gradient is not superposed or adjacent to the location of wave breaking generally. Further more, some researches [25] accounted for this phenomenon with the surface roller influence in the energy balance, in which part of the organized wave energy is first converted into forward momentum flux to the roller at wave breaking. The long-shore currents velocities appear to decay from their peak more slowly in seaward direction than in the shoreward direction. The main possible reason is that the decay of wave height is relatively intense in surf zone resulting in the remarkably gradients of wave radiation stress, and the combined effect of the lateral mixing and inertial convection also contribute to this phenomenon. It can be seen in Fig. 5 that the distribution of long-shore current velocity numerical results based on random waves in seaward decay more slowly than those based on regular waves and show better agreement with the field data, which is especially obvious in Case 2 an Case 3.

The predicted distribution of long-shore currents based on the numerical_1 model are shown in Fig. 6. As expected, the relatively strong and well developed wave-induced long-shore currents in the surf zone are present. The distribution of the long-shore currents in this whole coastal zone is approximately uniform. The currents velocities are uniform along the direction parallel to the shore line, whereas it can be seen in Fig. 6 that in the coastal area near $y=25 \mathrm{~m}$ where the water depth gradients is greater, the maximum long-shore currents velocities are slightly greater than those in other area. Since in such area the wave heights and wave heights gradients are both greater, the wave radiation stresses and wave radiation stresses gradients are also greater than those in else area correspondingly, which result in the greater long-shore currents velocities. On the other hand, the long-shore currents are approximately parallel to the coastal line on the whole, but in partial areas the current slightly deflects corresponding to the

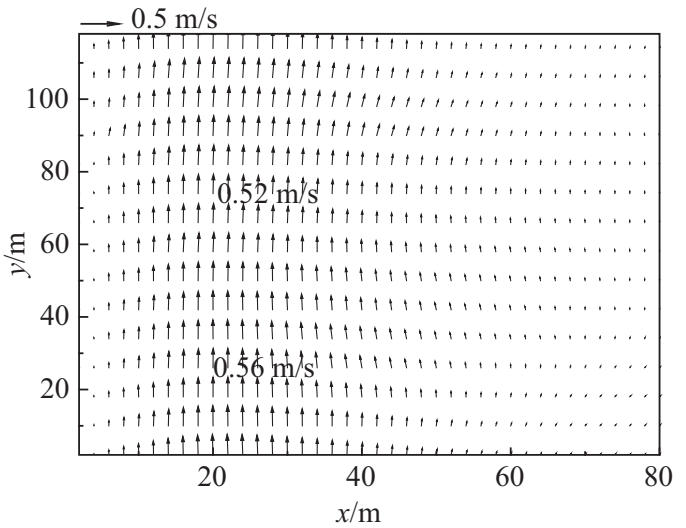

(a) Numerically simulated long-shore currents on Feb. 4

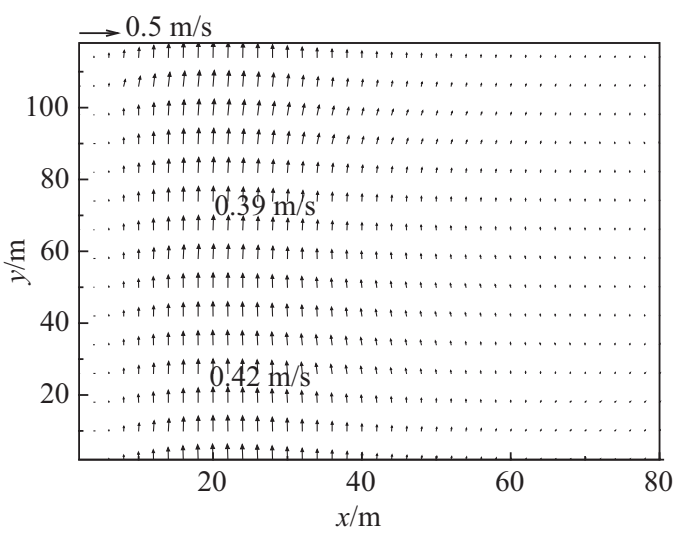

(b) Numerically simulated long-shore currents on Feb. 5

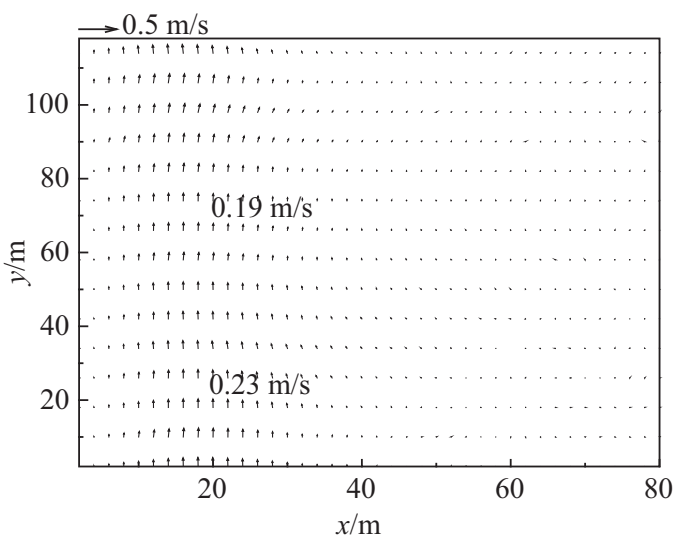

(c) Numerically simulated long-shore currents on Feb. 6

Fig. 6. Numerically simulated long-shore currents.

asymmetrical water depth gradients, such as the coastal areas near $y=25 \mathrm{~m}$ and $y=90 \mathrm{~m}$.

It should be pointed out incidentally that in the present numerical modeling validated by the NSTS experiment field data, although the numerical results based on both models are in good agreement with the field observations, the numerical_1 model results based on random waves give a slightly improved fit than the numerical 2 model results based on regular waves no matter for wave heights prediction or longshore currents prediction, as are shown in Fig. 3 and Fig. 5. 


\section{CONCLUSION}

The waves and near-shore currents formed by the breaking of obliquely incident water waves are most important hydrodynamics in coastal zones. It is very crucial to understand the distribution of them for coastal problems.

In this paper, the numerical study of random water waves and wave-induced long-shore currents at Leadbetter Beach, Santa Barbara, USA are presented based on the parabolic mild slope equation for the linear wave and near-shore current mathematical model, where the radiation stresses exerted on near-shore currents are calculated by the wave parameters in the parabolic mild slope equation. In the process of numerical modeling, it is found that the bathymetry gradient is determinant to the distribution of wave transformation and waveinduced long-shore current in this coastal zone. In the areas where the bathymetry gradients are greater, the break line is closer to the shoreline, and the radiation stresses and radiation stress gradients are both greater than else areas associating with the presence of the relatively greater maximum wave heights, which result in slightly greater wave-induced longshore currents. On the contrary, in the areas where the bathymetry gradients are small, the break line is farther from the shoreline, and the radiation stresses and radiation stress gradients are both less associating with the presence of the relatively less maximum wave heights, which result in slightly less wave-induced long-shore currents. Moreover, the waveinduced long-shore current deflects with the variation of bathymetry gradients. The numerical results agree well with the field measurements, and the numerical models based on the random wave show slightly better modeling effect than those based on regular wave.

\section{ACKNOWLEDGMENTS}

This research was financially supported by the Scientific Research Foundation of the Higher Education Institutions of Liaoning Province under Grant No. 2006T018, and by the National Natural Science Foundation of P. R. China under Grant No. 50839001.

\section{REFERENCES}

1. Allard, R., Dykes, J., Hsu, Y. L., Kaihatu, J., and Conley, D., "A real-time nearshore wave and current prediction system," Journal of Marine Systems, Vol. 69, No. 1-2, pp. 37-58 (2008).

2. Bettess, P. and Bettess, J. A., "A generalization of the radiation stress tensor," Applied Mathematical Modeling, Vol. 6, No. 3, pp. 146-150 (1982).

3. Birkemeier, W. A. and Dalrymple, R. A., "Nearshore water circulation induced by wind and waves," Proceedings of the Symposium on Modeling Techniques, San Francisco, Canada, ASCE, pp. 1062-1081 (1975).

4. Copeland, G. J. M., "Practical radiation stress calculations connected with equations of wave propagation," Coastal Engineering, Vol. 9, No. 3, pp. 195-219 (1985).

5. Dally, W. R., Dean, R. G., and Dalrymple, R. A., "Wave height variation across beaches of arbitrary profile," Journal of Geophysical Research, Vol. 90, No. NC6, pp. 1917-1927 (1985).
6. Ding, P. X., Kong, Y. Z., and Shi, F. Y., "Radiation stress of water waves and its calculation," Journal of East China Normal University, Vol. 1, pp. 82-87 (1998). (in Chinese)

7. Ebersole, B. A. and Dalrymple, R. A., "Numerical modeling of near-shore circulation," Proceeding of the 17th Conference on Coastal Engineering, Sydney, Australia, ASCE, Vol. 4, pp. 2710-2725 (1980).

8. Gable, C. G., "Report on data from the Near-shore Sediment Transport Study experiment on Leadbetter Beach, Santa Barbara, California," IMR Ref. 80-5, University of California, Institute of Marine Resources, La Jolla, California (1981).

9. Grasmeijer, B. T. and Ruessink, B. G., "Modeling of waves and currents in the nearshore parametric vs. probabilistic approach," Coastal Engineering, Vol. 49, No. 3, pp. 185-207 (2003).

10. Hsiao, S. S., Lin, M. C., and Hu, N. C., "Drbem analysis of combined wave refraction and diffraction in the presence of current," Journal of Marine Science and Technology, Vol. 10, No. 1, pp. 54-60 (2002).

11. Huo, G., Wang, Y. G., Yin, B. S., and You, Z. J., "A new measure for direct measurement of the bed shear stress of wave boundary layer in wave flume," Journal of Hydrodynamics, Ser. B, Vol. 19, No. 4, pp. 517-524 (2007).

12. Jin, Z. Q., "A hybrid turbulence model for numerical solution of longshore current and rip current," Journal of Hohai University, Vol. 16, No. 2 pp. 76-85 (1988). (in Chinese)

13. Kirby, J. T., "Open boundary-condition in parabolic equation method," Journal of Waterway, Port, Coastal, and Ocean Engineering, ASCE, Vol. 112, No. 3, pp. 460-465 (1986).

14. Kirby, J. T., "Rational approximations in the parabolic equation method for water waves," Coastal Engineering, Vol. 10, No. 4, pp. 355-378 (1986).

15. Larson, M. and Kraus, N. C., "Numerical model of longshore-current for bar and trough beaches," Journal of Waterway, Port, Coastal and Ocean Engineering, ASCE, Vol. 117, No. 4, pp. 326-347 (1991).

16. Lin, X., Yin B. S., Hou Y. J., Su, J. Z., and Cheng, M. H., "The effects of radiation stress on wave heights and sea level in the interaction of couple wave-tide-surge in the coastal area," Journal of Hydrodynamics, Ser. B, Vol. 15, No. 1, pp. 97-102 (2003).

17. Longuet-Higgins, M. S., "Long-shore currents generated by obliquely incident sea waves, 1," Journal of Geophysical Research, Vol. 75, No. 33, pp. 6778-6789 (1970).

18. Longuet-Higgins, M. S., "Long-shore currents generated by obliquely incident sea waves, 2," Journal of Geophysical Research, Vol. 75, No. 33, pp. 6790-6801 (1970).

19. Longuet-Higgins, M. S. and Stewart, R. W., "Radiation stress mass transport in gravity waves, with application to surf beats," Journal of Fluid Mechanics, Vol. 13, No. 4, pp. $481-504$ (1962).

20. MacMahan, J. H., Thornton, E. B., and Reniers, A. J. H. M., "Rip current review," Coastal Engineering, Vol. 53, No. 2-3, pp. 191-208 (2006).

21. Mei, C. C., "Note on the averaged momentum balance in 2-dimensional water waves," Journal of Marine Research, Vol. 31, No. 2, pp. 97-104 (1973).

22. Mirfenderesk, H. and Young, I. R., "Direct measurements of the bottom friction factor beneath surface gravity waves," Applied Ocean Research, Vol. 25, No. 5, pp. 269-287 (2003).

23. Myrhaug, D., "Bottom friction beneath random waves," Coastal Engineering, Vol. 24, No. 2-3, pp. 259-273 (1995).

24. Shen, Y. M., Tang, J., Zheng, Y. H., and Qiu, D. H., "Numerical simulation of wave current field in coastal zone based on parabolic mild slope equation," Chinese Journal of Hydraulic Engineering, Vol. 37, No. 3, pp. 301-307 (2006). (in Chinese)

25. Svendsen, I. A., "Mass flux and undertow in a surf zone," Coastal Engineering, Vol. 8, No. 4, pp. 347-365 (1984).

26. Tang, J., Shen, Y. M., Cui, L., and Qiu, D. H., "Numerical simulation of irregular water waves in coastal surf zones," ACTA Oceanologica Sinica, Vol. 30, No. 2, pp. 147-152 (2008). (in Chinese)

27. Wang, B. X., Chadwick, A. J., and Otta, A. K., "Derivation and application of new equations for radiation stress and volume flux," Coastal Engineering, Vol. 55, No. 4, pp. 302-318 (2008). 
28. Wu, C. S., Thornton, E. B., and Guza, R. T., "Waves and longshore currents: comparison of a numerical model with field data," Journal of Geophysical Research, Vol. 90, No. C3, pp. 4951-4958 (1985).

29. Yang, W. H., "Breaking wave spectrum and set-down set-up in shallow water," Journal of Marine Science and Technology, Vol. 1, No. 1, pp. 73-79 (1993)

30. Yoo, D. H., "Wave-induced longshore current in surf zone," Journal of Waterway, Port, Coastal and Ocean Engineering, ASCE, Vol. 120, No. 6 , pp. 557-575 (1994).

31. You, Z. J., "Increase of current bottom shear stress due to waves," Coastal Engineering, Vol. 26, No. 3-4, pp. 291-295 (1995).

32. Zheng, J. H. and Yan, Y. X., "Vertical variations of wave-induced radiation stress tensor," Journal of Hydrodynamics, Ser. A, Vol. 16, No. 2, pp. 246-253 (2001). (in Chinese)

33. Zheng, Y. H., Shen, Y. M., and Qiu, D. H., "Calculation of wave radiation stress in combination with parabolic mild slope equation," China Ocean Engineering, Vol. 14, No. 4, pp. 495-502 (2000).

34. Zheng, Y. H., Shen, Y. M., and Qiu, D. H., "Numerical simulation of wave height and wave set-up in nearshore regions," China Ocean Engineering, Vol. 15, No. 1, pp. 15-23 (2001).

35. Zheng, Y. H., Shen, Y. M., Qiu, D. H., and Xia, J., "Efficient elliptic solver for the mild slope equation using BI-CGSTAB method," China Ocean Engineering, Vol. 14, No. 2, pp. 175-184 (2000).

36. Zheng, Y. H., Shen, Y. M., Wu, X. G., and You, Y. G., "Determination of wave energy dissipation factor and numerical simulation of wave height in the surf zone," Ocean Engineering, Vol. 31, No. 8-9, pp. 1083-1092 (2004).

37. Zheng, Y. H., Shen, Y. M., and Xia, J., "Numerical solution of a mathematical model for water waves in large coastal areas" Acta Oceanologica Sinica, Vol. 19, No. 4, pp. 17-23 (2000). 